\section{Automatic and low-cost determination of BET surface areas}

\author{
H Bosch and A Peppelenbos \\ Department of Chemical Engineering, Twente University of \\ Technology, PO Box 217, Enschede, The Netherlands
}

\section{Received 18 October 1976, in final form 27 January 1977}

\begin{abstract}
A simple adsorption apparatus for a quick and reproducible determination of Brunauer-Emmett-Teller (BET) surface areas is described. The justification of proposing this device lies particularly in its flexibility, simplicity of construction and low price (Dfl. 1200, $\$ 400$ including liquid nitrogen level control). The dimensions and the influence of external variables are discussed quantitatively. An adsorption measurement proceeds as follows: the adsorbate (argon) passes through a capillary tube into the adsorption vessel, the flow being constant. The increase of pressure with time is recorded and compared with the blank (empty adsorption vessel). The blank does not depend on the adsorbent. It takes about one hour to determine a surface area of $100 \mathrm{~m}^{2}$. The reproducibility and accuracy are $3 \%$ or better for surface areas larger than $10 \mathrm{~m}^{2}$. Surface areas down to $1 \mathrm{~m}^{2}$ can be measured by a suitable decrease of the argon flow. It is also possible to use nitrogen as the adsorbate at the cost of somewhat more laborious calculations.
\end{abstract}

\section{Introduction}

Gas adsorption methods are widely used to determine specific areas of porous materials. A part of the adsorption isotherm has to be measured and from that isotherm the so called monolayer capacity $V_{\mathrm{m}}$ is calculated. This quantity is defined as the volume of adsorbate required to cover the accessible surface area with just one layer of adsorbate molecules. The specific surface area $S$ (in $\mathrm{m}^{2} \mathrm{~g}^{-1}$ ) can be calculated (see e.g. Gregg and Sing 1967) from

$$
S=\frac{V_{\mathrm{m}} N_{\mathrm{a}} \sigma}{\bar{V} w} \times 10^{-18}
$$

where $V_{\mathrm{m}}$ is the monolayer capacity $\left(\mathrm{cm}^{3} \mathrm{STP}\right), \sigma$ is the molecular cross sectional area $\left(\mathrm{nm}^{2}\right.$ molecule $\left.{ }^{-1}\right), N_{\mathrm{a}}$ is Avogadro's number, $w$ is the sample weight (g) after drying, and $\bar{V}$ is the molar volume of the adsorbate at STP $\left(\mathrm{cm}^{3}\right.$ STP $\left.\mathrm{mol}^{-1}\right)$.

For argon $\sigma=0.138 \mathrm{~nm}^{2}$ molecule ${ }^{-1}$ (Brunauer and Emmett 1937), based on the density of liquid argon extrapolated down to $77.3 \mathrm{~K}$. At relative pressures from 0.05 up to 0.25 , the adsorption on many porous materials is given by the adsorption isotherm of Brunauer, Emmett and Teller (BET). Linearization results in

$$
\frac{P_{\mathrm{r}}}{V_{\mathrm{a}}\left(1-P_{\mathrm{r}}\right)}=\frac{1}{V_{\mathrm{m}} C}+\frac{C-1}{V_{\mathrm{m}} C} P_{\mathrm{r}}
$$

where $P_{r}$ is the relative pressure of the adsorbate, equal to absolute pressure/saturation pressure at the temperature of the experiment, $V_{\mathrm{a}}$ is the amount adsorbed $\left(\mathrm{cm}^{3} \mathrm{sTP} \mathrm{g}^{-1}\right)$, and $C$ is the constant whose value depends on the heat of adsorption.

Plotting the left-hand side of equation (2) as a function of $P_{\mathrm{r}}$ should result in a straight line. In this case $V_{\mathrm{m}}$ can be calculated from the slope and the intercept. $V_{\mathrm{m}}$ is related to the specific surface area $S_{\text {BET }}$ through equation (1).

Sometimes $S_{\mathrm{BET}}$ is calculated from only one point of the adsorption isotherm (Drain and Morrison 1952, 1953). From equation (2) it can be deduced that this method is valid only if $C \gg 1+1 / P_{r}$, but a check on the assumption and applicability of the BET method is not possible.

A discussion of the basic assumptions in the BET model is beyond the scope of this paper (see for instance Sing 1964). Two cases which lead to wrong results by using a one-point method should, however, be noted. In the case that an appreciable amount of micropores is present, capillary condensation will occur. The amount adsorbed will be larger than predicted by the BET equation which concerns multilayer adsorption only. Calculation of $S_{\mathrm{BET}}$ from only one point of the adsorption isotherm results in a value which is too high. A plot according to equation (2) will show clearly the presence of micropores by a deviation from a straight line which is convex with respect to the abscissa. On the other hand, the adsorption might be limited by the pore diameter to only a few adsorbed layers, which results in a concave deviation indicating that equation (2) is not valid in that particular case. These possibilities might occur, notwithstanding that the condition $C \gg 1 / P_{\mathrm{r}}$ is satisfied (compare table 2 ).

Thus for routine determinations one needs a cheap, automatic adsorption device, estimating about five points of the adsorption isotherm in a relatively short time, to check whether or not the BET equation is applicable. In this paper such a low-budget device is described. In fact it is a simplification of the apparatus developed by Schlosser (1959); its conception was already outlined by Scholten (1965). The construction and its application will be discussed.

\section{Experimental}

2.1 Description of the apparatus

An outline of the apparatus is given in figure 1. The capillary tube $\mathrm{C}(L=30 \mathrm{~cm}$, internal diameter $0.1 \mathrm{~mm})$ is connected

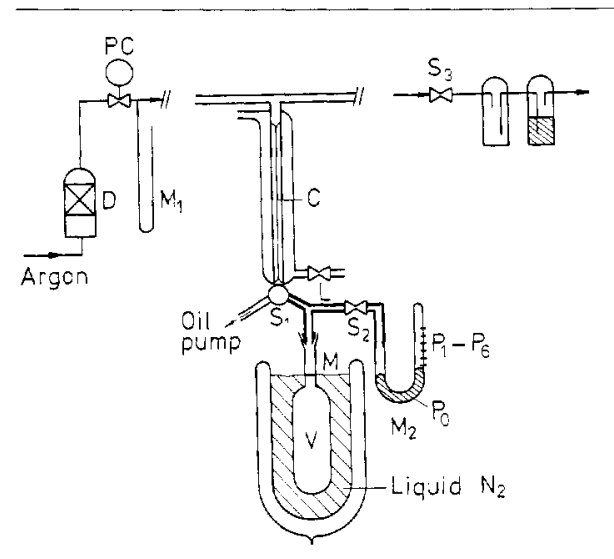

Figure $1 \mathrm{D}$, drying with molecular sieve $3 \mathrm{~A}$; PC, pressure control; $\mathrm{M}_{1}$, manometer; $\mathrm{C}$, capillary tube $\dagger ; L \approx 0.3 \mathrm{~m}$, ID $=0.1 \mathrm{~mm} ; S_{1}$, three-way stopcock; $V$, adsorption vessel, volume about $200 \mathrm{~cm}^{3} ; M$, marker; $S_{2}, S_{3}$, vacuum stopcocks; $\mathrm{M}_{2}$, mercury manometer, $\mathrm{ID}=6 \mathrm{~mm} ; \mathrm{P}_{0}-\mathrm{P}_{6}$, platinum contacts; L, Pyrex tube, $\mathrm{ID}=2 \mathrm{~mm}$

$\dagger$ Capillary tube with precision bore supplied by Pulles and Hanique, Eindhoven, The Netherlands. 
through a three-way stopcock $\mathrm{S}_{1}$ with a rotatory oil pump, the adsorption vessel $\mathrm{V}$ and the mercury manometer $\mathrm{M}_{2}$. At the other side a constant pressure of $104.0 \mathrm{kPa}$ is maintained by pressure controller PC. The volume of the adsorption vessel amounts to about $200 \mathrm{~cm}^{3}$, large enough for one to neglect a sample volume up to $3 \mathrm{~cm}^{3}$. In other words, the blank (pressure increase as a function of time with an empty vessel) is a constant of the apparatus.

The vacuum section of $\mathbf{M}_{2}$ is provided with seven platinum wires $\mathbf{P}_{0}-\mathbf{P}_{6}$, the distances between $\mathbf{P}_{1}-\mathbf{P}_{6}$ being $4 \mathrm{~mm}$ each. $\mathbf{P}_{0}$ serves as the common electrode. A short-circuited $\mathbf{P t}$ contact switches off the corresponding clock via a relay. It is also possible to use telephone counters, driven by a $1 \mathrm{~Hz}$ pulse signal, or a (far more expensive) pressure transducer for continuous measurements (Dollimore et al 1973). Several adsorption devices may be connected to the same main line and oil pump. The total cost of a set-up consisting of one pressure controller, one vacuum pump, three adsorption devices, each fitted with six clocks, and two simple level controllers, amounts to about $\$ 1200$.

\subsection{Principle of operation}

The method as given by Schlosser (1959) is a dynamic one; during an experiment the adsorbate flows continuously through the capillary tube into the adsorption vessel.

This method is also a volumetric one, in which the adsorbed amount is calculated by comparing the blank with the pressure increase against time in the presence of an adsorbing sample. Schlosser compensates for the amount of gas which is not adsorbed, but which has built up the gas pressure, by having a separate but equal gas fiow in an empty vessel of the same size and at the same temperature as the adsorption vessel. The pressure difference between both vessels must be recorded, as well as the pressure itself.

The blank is a constant of the apparatus, as mentioned above, and will be discussed later. Apart from check measurements, this blank has to be estimated just once. The differential manometer and blank vessel are not essential and therefore not inserted in our set-up.

In the presence of an adsorbent the gas will be partly adsorbed and it takes more time to reach a certain pressure $P$. The adsorbed amount at that pressure, $V_{a}$, can be calculated from

$$
\left[V_{\mathrm{a}}=\phi_{V}(\mathrm{STP}) \Delta t\right]_{P},
$$

each variable mentioned being dependent upon the pressure, where $\phi_{V}$ (STP) is the volume flow through the capillary tube $\left(\mathrm{cm}^{3} \mathrm{~min}^{-1}\right.$ ) and $\Delta t$ is the extra time (min) to reach pressure $P$, compared to a blank experiment.

The volume flow rate of a laminar gas flow through a tube is calculated from a modified Poiseuille equation:

$$
\phi_{V}(\mathrm{STP})=60 \frac{P_{\mathrm{f}}^{2}-P^{2}}{101 \cdot 3} \frac{273}{T} \frac{\pi r^{4}}{16 \eta L}
$$

where $P_{\mathrm{f}}$ is the fore pressure ( $\left.\mathrm{kPa}\right), P$ the back pressure (kPa), $T$ the temperature of the capillary tube (K), $L$ the length of the tube $(\mathrm{mm}), r$ the internal radius of the tube $(\mathrm{mm})$ and $\eta$ the coefficient of viscosity ( $\mathrm{Pa} \mathrm{s}$ ).

A rise of the back pressure to $8 \mathrm{kPa}$ results in a decrease of $\phi_{V}$ of only $0.6 \%$, the fore pressure being set to about $104 \mathrm{kPa}$. Equation (4) should be valid for all gases to be considered because the Reynolds number is always less than 25 , given the dimensions mentioned above. To ensure a constant volume flow rate, thus permitting a ready calculation of the amount adsorbed, a back pressure of $8 \mathrm{kPa}$ should correspond with a relative pressure of 0.25 . Hence, argon is the obvious adsorbate. Its saturation pressure at the temperature of liquid nitrogen $\left(T_{\mathrm{N}}=77.3 \mathrm{~K}\right)$ is calculated from the metastable extension of the boiling curve to be $30.7 \mathrm{kPa}$.

Although argon is known to be a very suitable adsorbate for surface area determinations (Corrin 1951), the results are consistently $10-20 \%$ lower compared with nitrogen adsorption (using $\sigma_{\mathrm{Ar}}=0.138 \mathrm{~nm}^{2}, \sigma_{\mathrm{N}}=0.162 \mathrm{~nm}^{2}$ ) (Emmett and Brunauer 1937, Kodera and Onishi 1959, Honig and Reyerson 1952). Excellent agreement is obtained, however, by making an arbitrary adjustment in $\sigma_{\mathrm{Ar}}$, ranging from 0.157 to $0.166 \mathrm{~nm}^{2}$ (Kodera and Onishi 1959, Corrin 1951, Rhodin 1953, Harkins 1952).

\subsection{Experimental procedure}

The left-hand side of manometer $\mathrm{M}_{2}$ is evacuated before the adsorption vessel is attached. The sample must be heated in vacuo to remove adsorbed material. The temperature should be as high as possible without changing the properties of the sample, e.g. by sintering or melting. The resulting weight loss has to be determined separately. During heating stopcock $S_{2}$ is closed to keep the mercury clean. The fore pressure is set to about $104 \mathrm{kPa}$. After cooling down to room temperature, a Dewar with liquid nitrogen is put into position round vessel $\mathrm{V}$. The level of the liquid nitrogen must fall together with marker $M$ very accurately. Level control is achieved either automatically (Abouritz and Cath 1967) or by hand. After thermal equilibrium is achieved, the oil pump is connected to tube $\mathrm{C}$ through stopcock $S_{1}$ to establish the rate profile in the tube. Stopcock $\mathrm{S}_{2}$ is opened. The experiment is started by connecting the capillary tube with the adsorption vessel. Simultaneously all clocks are switched on with a main switch. The calculating procedure is illustrated in figure 2. $V_{\mathrm{m}}$ is calculated from the plot according to equation (2), and $S_{\mathrm{BET}}$ is calculated from equation (1).

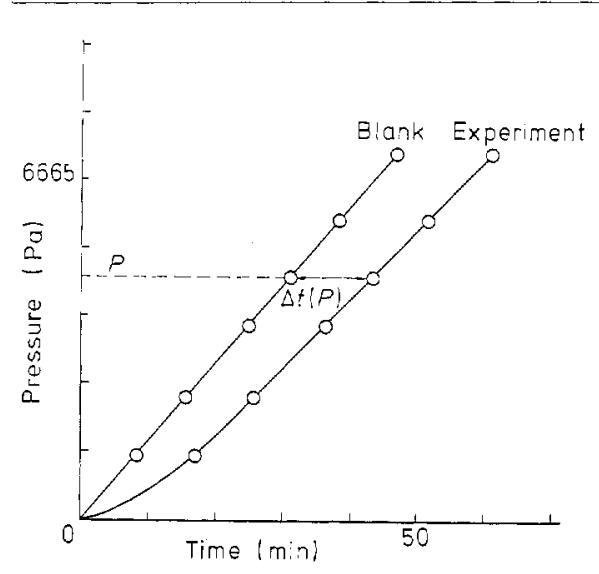

Figure 2 Typical result, in this case of the adsorption on a molybdenum catalyst. $\phi_{V}=1.03 \mathrm{~cm}^{3}$ STP $\mathrm{min}^{-1}$; dry sample weight is $0.233 \mathrm{~g} ; V_{\mathrm{a}}$ is calculated from equation (3); $S_{\mathrm{BET}}=195 \pm 4 \mathrm{~m}^{2} \mathrm{~g}^{-1} ; C=63$

The pressures at which the Pt contacts are closed successively are calibrated against a water manometer.

The volume flow rate is determined from two blank experiments, using successively two empty vessels of a known difference in volume $\Delta V$. At each pressure $P$ the flow rate $\phi_{V}$ (in $\mathrm{cm}^{3}$ STP $\mathrm{min}^{-1}$ ) can be calculated analogously to the procedure illustrated in figure 2 :

$$
\phi_{V}(\mathrm{STP})=\frac{\Delta V}{\Delta t(P)} \frac{P}{R T_{N}} \bar{V}
$$

where $R$ is the gas constant.

Since $\phi_{V}$ can be considered to be constant, in a pressuretime plot blanks will be straight lines through the origin. 
Therefore $\phi_{V}\left(\mathrm{~cm}^{3}\right.$ STP $\left.\mathrm{min}^{-1}\right)$ can be calculated more accurately from both slopes $s_{\mathrm{I}}$ and $s_{\mathrm{II}}$ :

$$
\phi_{V}(\mathrm{STP})=\frac{\Delta V}{1 / s \mathrm{II}-1 / s_{\mathrm{I}}} \frac{\bar{V}}{R T_{\mathrm{N}}} .
$$

\section{Results}

The volume flow rate was calculated as a function of fore pressure (ranging from 86.9 to $117.3 \mathrm{kPa}$ ) from the pressure increase with time by means of equation (6). The resulting flow rates agree very well $( \pm 1 \%)$ with those calculated from equation (4) with $L=295 \mathrm{~mm}, r=0.05 \mathrm{~mm}$ and $\eta_{298}=22.7 \times$ $10^{-6} \mathrm{~Pa}$ s. Hence, if a capillary tube is calibrated, each flow rate can be chosen within certain limits by setting the appropriate fore pressure.

To ensure a close approach of the adsorption equilibrium, the dosing rate of argon, that is the flow rate through the capillary tube, must be small compared with the rate of adsorption. The rate of adsorption is proportional to the sample weight. We have varied the ratio of flow rate and sample weight 40 -fold (table 1). The experimental deviation did not exceed the overall reproducibility $( \pm 3 \%$ ) (table 3 ). Thus, a volume flow rate of about $1 \mathrm{~cm}^{3}$ STP min'-1 is suitable.

The reliability of the apparatus was tested by comparison with the commercially available 'Sorptomatic' (Carlo Erba, Milan), in which a static volumetric method was applied. The excellent agreement between the dynamic and the static operations suggests a reliability which is far better than $3 \%$ as mentioned above (see table 2).

From this multipoint method it is indicated that e.g. the pore structure of both types of chromium oxides will be different, notwithstanding that their surface areas look equal.

Table 1 Results of varying the flow rate/sample weight ratio. Sample $\mathrm{Al}_{2} \mathrm{O}_{3}$, dried for $2 \mathrm{~h}$ at $873 \mathrm{~K}$; adsorbate : argon

\begin{tabular}{|c|c|c|c|}
\hline $\begin{array}{l}\text { Flow rate } \\
\left(\mathrm{cm}^{3} \mathrm{sTP} \mathrm{min}^{-1}\right)\end{array}$ & $\begin{array}{l}\text { Weight } \\
\text { (g) }\end{array}$ & $\begin{array}{l}\text { Ratio } \\
\left(\mathrm{cm}^{3} \operatorname{sTP} \min ^{-1} \mathrm{~g}^{-1}\right)\end{array}$ & $\begin{array}{l}\text { Specific surface area } \\
\left(\mathrm{m}^{2} \mathrm{~g}^{-1}\right)\end{array}$ \\
\hline $0 \cdot 34$ & $2 \cdot 303$ & $0 \cdot 15$ & $225 \pm 2$ \\
\hline $1 \cdot 06$ & $1 \cdot 575$ & 0.67 & $229 \pm 5$ \\
\hline $1 \cdot 03$ & 0.609 & $1 \cdot 07$ & $230 \pm 5$ (triple) \\
\hline $1 \cdot 03$ & 0.620 & $1 \cdot 66$ & $231 \pm 2$ \\
\hline $1 \cdot 03$ & 0.414 & $2 \cdot 49$ & $234 \pm 4$ \\
\hline $0 \cdot 81$ & $0 \cdot 224$ & $3 \cdot 61$ & $229 \pm 9$ \\
\hline \multirow[t]{2}{*}{$1 \cdot 55$} & 0.256 & $6 \cdot 05$ & $237 \pm 3$ \\
\hline & & Average & $230 \pm 5$ \\
\hline
\end{tabular}

Table 2 Accuracy and reproducibility. The number of experiments is given in parentheses

\begin{tabular}{|c|c|c|c|c|c|}
\hline \multirow[t]{2}{*}{ Sample } & \multicolumn{2}{|c|}{ Dynamic } & \multicolumn{2}{|c|}{ Static } & \multirow[t]{2}{*}{ Remarks } \\
\hline & $S_{\mathrm{BET}}\left(\mathrm{m}^{2} \mathrm{~g}^{-1}\right)$ & $C$ & $S_{\mathrm{BET}}\left(\mathrm{m}^{2} \mathrm{~g}^{-1}\right)$ & $C$ & \\
\hline$\gamma \mathrm{Al}_{2} \mathrm{O}_{3}$ & $230 \pm 6(9)$ & 46 & $231 \pm 4(3)$ & 50 & $\begin{array}{l}\text { The sample weight/flow rate ratio } \\
\text { was varied } 40 \text {-fold }\end{array}$ \\
\hline Mo catalyst & $195 \pm 5(3)$ & 70 & $190 \pm 5(2)$ & 73 & $\begin{array}{l}\text { Prepared from an } \mathrm{NH}_{4} \mathrm{~F} \\
\text { molybdate solution }\end{array}$ \\
\hline Ketjenfine & $235 \pm 5(2)$ & 51 & $235 \pm 5$ & 51 & \\
\hline Silica-alumina & $441 \pm 15(2)$ & 21 & $450 \pm 20(2)$ & 27 & \\
\hline $\mathrm{CeO}_{2}$ & $52 \pm 6(5)$ & 一 & - & 一 & $\begin{array}{l}\text { Prepared (Potman and Van } \\
\text { Ommen } 1975 \text { ) by heating } \\
\mathrm{Ce}_{2}\left(\mathrm{C}_{2} \mathrm{O}_{4}\right)_{3} \text { at } 673-773 \mathrm{~K} \text { for } \\
6-71 \mathrm{~h}\end{array}$ \\
\hline $\mathrm{CeO}_{2}$ sintered & $10 \pm 1$ & 50 & $10 \pm 1(2)$ & 42 & \\
\hline $\mathrm{Cr}_{2} \mathrm{O}_{3}$ & $255 \pm 5$ & 41 & - & - & $\begin{array}{l}\text { Prepared (Potman and Van } \\
\text { Ommen } 1975 \text { ) by precipitating } \\
\mathrm{Cr}\left(\mathrm{NO}_{3}\right)_{3} \text { with } \mathrm{NH}_{3} \text { and heating } \\
\text { the } \mathrm{Cr}(\mathrm{OH})_{3} \text { obtained }\end{array}$ \\
\hline $\mathrm{Cr}_{2} \mathrm{O}_{3}$ & About 250 & About 700 & - & - & $\begin{array}{l}\text { Prepared by homogeneous } \\
\text { precipitation of } \mathrm{Cr}(\mathrm{OH})_{3} \text {. } \\
\text { BET plot did not show a straight } \\
\text { line }\end{array}$ \\
\hline Mg stearate & $12 \pm 2$ & 8 & 一 & - & $\begin{array}{l}\text { Dried at } 323 \mathrm{~K} \text { and } \approx 1.33 \mathrm{~Pa} \text { for } \\
1 \mathrm{~h}\end{array}$ \\
\hline $\mathrm{MgO}$ & $114 \pm 3(2)$ & 38 & $116 \pm 5(2)$ & 50 & \\
\hline RBW-1 (active carbon) & About $960(3)$ & $<0$ & - & - & $\begin{array}{l}\text { BET plot did not show a straight } \\
\text { line }\end{array}$ \\
\hline Na-KF (carbon black) & $89 \pm 4$ & 110 & $83 \pm 3(2)$ & 175 & \\
\hline Sterling MT-FF (carbon black) & $9 \pm 1(2)$ & 92 & $9 \pm 1(2)$ & 92 & \\
\hline
\end{tabular}


Table 3 Influence of fluctuations on the accuracy of the surface area determination

\begin{tabular}{|c|c|c|c|c|c|}
\hline Changes in: & $\begin{array}{l}\text { Magnitude } \\
\text { (illustrative) }\end{array}$ & Consequence & $\begin{array}{l}\text { Resulting } \\
\text { error in } \\
S_{\text {BET }}(\%)\end{array}$ & $\begin{array}{l}\text { Calculated } \\
\text { from } \\
\text { equation: }\end{array}$ & Remedy \\
\hline Barometric pressure & $-3 \mathrm{kPa}$ & $\begin{array}{l}\Delta P_{V}=2 \cdot 8 \% \\
\Delta T_{\mathrm{N}}=-0.24 \mathrm{~K}\end{array}$ & $\begin{array}{l}+5 \cdot 6 \\
+0 \cdot 3\end{array}$ & $\begin{array}{l}(4) \\
(7)\end{array}$ & $\begin{array}{l}\text { A pressure controller should } \\
\text { be used }\end{array}$ \\
\hline Liquid nitrogen level & $-5 \mathrm{~mm}$ & $\begin{array}{l}\Delta V_{\mathrm{r}}=+0.8 \mathrm{~cm}^{3} \\
\Delta V_{\mathrm{N}}=-0.8 \mathrm{~cm}^{3}\end{array}$ & -3 & (7) & $\begin{array}{l}\text { Careful level control, either } \\
\text { manual or automatic }\end{array}$ \\
\hline $\begin{array}{l}\text { Room temperature small-term } \\
\text { fluctuations }\end{array}$ & $+1 \mathrm{~K}$ & & $+0 \cdot 3$ & (7) & $\begin{array}{l}\text { The water mantle should be } \\
\text { thermostated when large }\end{array}$ \\
\hline Long-term changes & $+5 \mathrm{~K}$ & $\Delta T=+5 \mathrm{~K}$ & $+1 \cdot 5$ & (4) & seasonal effects are expected \\
\hline
\end{tabular}

\section{Discussion}

To derive a relation which connects the dimensions of the apparatus with the pressure increase against time, we assume the low-pressure side of the capillary to be made up of two sections. One section is at room temperature $T_{\mathbf{r}}$ with volume $V_{\mathrm{r}}$, the other one with volume $V_{\mathrm{N}}$ is at $T_{\mathrm{A}}$. From a mole balance, assuming an ideal gas state, the pressure increase in an empty vessel becomes

$$
\frac{\mathrm{d} P}{\mathrm{~d} t}=\frac{\phi_{V}(\mathrm{STP})}{\bar{V}} \frac{R T_{\mathrm{N}} / V_{\mathrm{N}}}{1+\left(V_{\mathrm{r}} / V_{\mathrm{N}}\right)\left(T_{\mathrm{N}} / T_{\mathrm{T}}\right)} .
$$

Variations of the sample volume ( $1 \mathrm{~cm}^{3}$ in order of magnitude) have no noticeable effect if $V_{\text {sample }} \ll V_{\mathrm{r}}$. This demand is satisfied with $V_{x} \approx 200 \mathrm{~cm}^{3}$. A higher value leads to an unnecessary extension of the experimental time at a gas flow rate of $1 \mathrm{~cm}^{3} \mathrm{~min}^{-1}$. From equations (2) and (7) it is calculated that surface area determinations from 10 to $200 \mathrm{~m}^{2}$ take 30-90 min. It is advisable to decrease the gas flow rate (using equation (4)) when surface areas of 1-10 $\mathrm{m}^{2}$ are to be determined.

In fact $V_{r}$ is not constant, but increases with pressure because of the falling mercury level. Since an average value of $V_{\mathrm{r}}$ is about $10 \mathrm{~cm}^{3}$, the right-hand side of the denominator becomes 0.012 , which can be neglected compared to unity, resulting in a constant value of $\mathrm{d} P / \mathrm{d} t$ when no adsorption takes place.

$V_{\mathrm{N}}$ was determined very accurately from the slope of two blanks at $T_{\mathrm{N}}=77.3$ and $298 \mathrm{~K}$ respectively. The result agrees within $0.3 \%$ with a direct measurement of the volume up to marker $\mathbf{M}$. Clearly, the influence of the temperature gradient from $T_{\mathrm{r}}$ down to $77.3 \mathrm{~K}$ can be neglected. Moreover, any possible influence which affects the adsorption experiment and the blank in the same way can be neglected.

A fluctuation in barometric pressure, room temperature or liquid nitrogen level during an adsorption experiment causes a deviation of the calibrated blank, leading to inaccuracy of the specific surface area to be determined. All effects can be calculated from equation (4) or (7) and are summarized in table 3. Major effects can be eliminated by the use of a pressure controller and a liquid nitrogen level controller, as described above.

The applicability of this apparatus is not limited to the measurement of BET surface areas down to $1 \mathrm{~m}^{2} \mathrm{~g}^{-1}$ with argon. Smaller surface areas can be measured by an appropriate increase of the sample weight. Since $V_{N}$, the volume of the adsorption vessel at $77 \cdot 3 \mathrm{~K}$, will be influenced, the blank must be corrected by means of equation (7).

Nitrogen might be used as the adsorbate. The volume flow rate is not constant but can be calculated at each pressure by means of equation (4). This is more laborious, but with computerized calculations this is not a serious disadvantage. In this case, data beyond the BET region can also be processed, giving rise to an extended adsorption isotherm.

\section{Acknowledgments}

The authors wish to acknowledge B Snijders and Dr M H G M Steijns who carried out part of the experimental work with very great accuracy. They also wish to express gratitude to Dr P Mars for his helpful suggestions.

\section{References}

Abouritz G and Cath P G 1967 J. Sci. Instrum. 94156

Brunauer S and Emmett P H 1937 J. Am. Chem. Soc. 59 2682

Corrin M L $1951 \mathrm{~J}$. Am. Chem. Soc. 734061

Dollimore D, Rickett $\mathrm{G}$ and Robinson R 1973 J. Phys. E: Sci. Instrum. 694

Drain L E and Morrison J L 1952 Trans. Faraday Soc. 48 1849

Drain L E and Morrison J L 1953 Trans. Faraday Soc. 49 654

Emmett P H and Brunauer S 1937 J. Am. Chem. Soc. 591553

Gregg S J and Sing K S W 1967 Adsorption, Surface Area and Porosity (London: Academic) p 35

Harkins W D 1952 The Physical Chemistry of Surface Films (New York: Reinhold) p 227

Honig J N and Reyerson L H $1952 J$. Phys. Chem. 56140

Kodera K and Onishi Y 1959 J. Jap. Chem. Soc. 32356

Potman W and Van Ommen J G 1975 Mikrochim. Acta 1633

Rhodin T N 1953 J. Phys. Chem. 571437

Schlosser E G 1959 Chem. Ing. Tech. 31799

Scholten J J F 1965 Proc. Br. Ceram. Soc. 5120

Sing K S W 1964 Chem. Ind. 321

Journal of Physics E: Scientific Instruments 1977 Volume 10 Printed in Great Britain (C) 1977 